\title{
Factors affecting the initiation and continuation of maternal health service utilization among women who delivered in the past one year in Enemay district, East Gojjam, Ethiopia
}

\author{
Anguach Shitie ${ }^{1}$ and Zelalem Nigussie Azene ${ }^{2^{*}}$ (1)
}

\begin{abstract}
Background: Maternity continuum of care is the continuity of maternal healthcare services that a woman uses, which includes antenatal care (ANC 4+), skilled birth attendant (SBA), and postnatal care (PNC) within $48 \mathrm{~h}$ of delivery. It is one of the essential strategies for reducing maternal and newborn morbidity and mortality. Therefore, this study aimed to assess the prevalence and factors affecting the initiation and continuation of maternal health service utilization among women who delivered in the past one year in Enemay district, East Gojjam zone, Ethiopia.

Methods: A community-based cross-sectional study was conducted among six hundred twenty-one (621) women who gave birth in the last one year in Enemay district from February 25 to March 10, 2019. A simple random sampling technique was used to select the study participants. Data were collected by face-to-face intervieweradministered, pretested, and semi-structured questionnaire. Binary logistic regressions (bi-variable and multivariable) were fitted to identify statistically significant variables. Adjusted Odds Ratio (AOR) with 95\% Confidence Interval (CI) was used to declare statistically significant variables on the basis of $p$-value $<0.05$ in the multivariable binary logistic regression.
\end{abstract}

Results: In this study, around $61 \%$ of women had antenatal care follow-up. Out of those women having ante natal care follow-up, about $77.5 \%$ (95\% Cl 73, 81.7\%) had continued to receiving skilled birth delivery service. Age (AOR= $1.795 \% \mathrm{Cl}:(1.0,2.88))$, marital status (AOR $=1.6,95 \% \mathrm{Cl}:(1.01,2.76))$, women's educational status (AOR $=2.9,95 \% \mathrm{Cl}$ : $(1.30,6.72))$, autonomy for health care decision-making $(A O R=3.71,95 \% \mathrm{Cl}:(2.36,6.02))$, exposure to media $(A O R=$ $2.8,95 \% \mathrm{Cl}:(1.78,4.6))$, wanted pregnancy (AOR $=3.695 \% \mathrm{Cl}:(2.2,5.95))$, and parity (AOR $=0.34,95 \% \mathrm{Cl}:(0.16,0.71))$ were statistically significant variables associated with initiation of antenatal care, whereas educational status of women $(A O R=4.65,95 \% \mathrm{Cl}:(1.37,15.7))$, autonomy for health care decision making (AOR=2.62, 95\% Cl:(1.0, 6.82)), and had counseled during antenatal care (AOR $=2.8895 \% \mathrm{Cl}:(1.21,6.83))$ were statistically significant variables associated with the continuation of maternal health care services.

\footnotetext{
* Correspondence: zniqussie35@gmail.com

${ }^{2}$ Department of Women's and family health, School of Midwifery, College of Medicine and Health Sciences, University of Gondar, Gondar, Ethiopia

Full list of author information is available at the end of the article
}

(c) The Author(s). 2021 Open Access This article is licensed under a Creative Commons Attribution 4.0 International License, which permits use, sharing, adaptation, distribution and reproduction in any medium or format, as long as you give appropriate credit to the original author(s) and the source, provide a link to the Creative Commons licence, and indicate if changes were made. The images or other third party material in this article are included in the article's Creative Commons licence, unless indicated otherwise in a credit line to the material. If material is not included in the article's Creative Commons licence and your intended use is not permitted by statutory regulation or exceeds the permitted use, you will need to obtain permission directly from the copyright holder. To view a copy of this licence, visit http://creativecommons.org/licenses/by/4.0/. The Creative Commons Public Domain Dedication waiver (http://creativecommons.org/publicdomain/zero/1.0/) applies to the data made available in this article, unless otherwise stated in a credit line to the data. 
Conclusions: This study demonstrated that the initiation and continuity of maternal health care services are low in the study area. Age, marital status, residence, women's educational status, health care decision-making autonomy, exposure to media, wanted pregnancy, and parity were factors significantly affecting the initiation of antenatal care. Whereas, women's educational status, health care decision-making autonomy, and counseling during antenatal care were predictors influencing the continuation of maternal health care services (antenatal care to skilled birth delivery).

Keywords: Antenatal care, Initiation, Continuation, Maternal health care services, Utilization, Ethiopia

\section{Background}

Utilization of maternal healthcare service is essential for the improvement of both maternal and child health, reduction of maternal and child mortality, but the continuity of maternal health care utilization has been a challenge in Sub-Saharan Africa. Many mothers who attend antenatal care visits fail to use facility delivery [1, 2]. Antenatal care (ANC) is crucial to provide information for identifying and treating existing social and medical conditions, health promotion, and screening of risk factors. However, receiving only antenatal care is not enough since the majority of the fatal complications occur at the time of labor and delivery. Therefore, women should have a skilled birth attendant (SBA) from trained and qualified professionals for safe childbirth as failure to access skilled assistance during delivery results in too many complications [2-4]. Maternal mortality is unacceptably high. About 295,000 women died during and following pregnancy, and childbirth in 2017. The vast majority of these deaths (94\%) occurred in lowresource settings and most of the deaths could have been prevented. Most of the deaths occur during labor, delivery and the immediate postpartum period [5]. Ethiopia is one of the countries with the highest maternal mortality levels in the world, with an estimated 412 deaths per 100,000 live births [6].

The maternal mortality ratio and lifetime risk of maternal mortality were 20 and 27 times higher in developing countries when compared to developed ones. For subsequent reduction of maternal mortality, a sustainable development goal was developed, which targets decreasing the global maternal mortality ratio to less than 70 per thousand live births and neonatal mortality to less than 12 per 1000 in all countries by 2030 [7]. In order to achieve this ambitious goal, better access to maternal and reproductive health care services including antenatal care in pregnancy, skilled care during childbirth, and postnatal care service is required [8]. From a global perspective, it is estimated that approximately $80 \%$ of maternal deaths and up to twothirds of neonatal deaths could be prevented if effective health measures are taken during birth and the first week of life [9]. However, utilization of these services in most developing countries is low due to various cultural, socioeconomic, and demographic factors.
Maternal mortality has a negative impact on living children, families, and economic growth. Newborns and children whose mothers died from maternal causes face nutrition deficits, and are less likely to access the needed health care services. Older children drop out of school to care for younger siblings and often choose migration in search of better opportunities and family fragmentation is common following a maternal death $[11,12]$. Maternal mortality has also impacted economic growth. A study done in the African region showed that maternal mortality has a statistically significant negative effect on GDP, which results in an annual loss of US\$49,224 $[10,11]$.

In Ethiopia, 62\% of women received antenatal care whereas only $28 \%$ were assisted by skilled delivery attendants, which shows a great discontinuity rate [6]. However, studies on factors influencing maternal care initiation or continuation were not available in Ethiopia. The objective of this study was, therefore, to assess the prevalence and factors affecting initiation and continuation of maternal health service utilization among women who delivered in the past one year in Enemy district, East Gojjam zone, Ethiopia.

\section{Methods \\ Study area}

The study was conducted in Enemay district, Amhara regional state, Northwest Ethiopia. The administrative center of this district is Bichena. The district is located in East Gojjam Zone, Amhara regional state, and is 270 $\mathrm{kms}$ far from Addis Ababa, the capital of Ethiopia in the Northwest direction and, about $295 \mathrm{~km}$ from Bahir Dar city, the capital of Amhara regional state. According to the 2017 statistical figure of Enemay district health office report, the total population in the district is around 198,241. The district has now 7 health centers, 35 health posts, and 1 hospital. All these health institutions are currently providing maternal and child health care services.

\section{Study design and period}

A community-based cross-sectional study was conducted from February 25 to March 10, 2019. 


\section{Population}

\section{Source population}

All women who gave birth in the last one year in Enemay district.

\section{Study population}

All women who gave birth in the last one year in the selected Kebeles of Enemay district.

\section{Eligibility Criteria}

\section{Inclusion criteria}

All women who gave birth in the last one year and lived at least six months in Enemay district.

\section{Exclusion criteria}

Those women who were severely ill and unable to communicate effectively were excluded from the study.

\section{Sample size determination and sampling procedures}

The sample size was determined for the first and second objectives. Finally, the largest sample size was taken. Single population proportion [12] was used to calculate the sample size for the first objective by assuming the proportion of antenatal care utilization in rural areas of India, which was $74 \%$ [13] with a 95\% confidence level, and $5 \%$ marginal error. Based on these assumptions, the total sample size was calculated using the following formula:

$$
\begin{aligned}
& \frac{\mathrm{n}=(\mathrm{z \alpha} / 2) 2 \mathrm{p}(1-\mathrm{p})}{\mathrm{d} 2} \frac{\mathrm{n}=(1.96) 2(0.74(1-0.74)}{(0.05) 2} \\
& =296
\end{aligned}
$$

Where $\mathrm{n}=$ required sample size, $\mathrm{Z}=$ critical value for normal distribution at 95\% confidence level (1.96), $\mathrm{P}=$ Proportion of antenatal care utilization, $\mathrm{d}=0.05$ (5\% margin of error). By considering a $10 \%$ non-response rate and a design effect of 2 , the final sample size was found to be 651 .

First, the population was stratified by residence as urban and rural Kebeles. The residential stratification gave 28 rural and 8 urban kebeles. Out of those, three urban and eight rural kebeles were selected randomly by using a lottery method. Totally, 11 kebeles were selected from the total.

thirty six kebeles by a simple random sampling method. The number of women who delivered in each selected kebele was taken from the health extension workers' registration book. Then, the sample was proportionally allocated for each selected kebele. Finally, a simple random sampling technique was employed to select the women by using guidance.

Either of the mothers was interviewed in households having two mothers who gave birth in the last one year in the district. Households that were closed during the data collection period were revisited.

\section{Data collection tool and procedures}

Data were collected using a pretested, semi-structured, and interviewer-administered questionnaire. The questionnaire was developed after reviewing relevant literature. It was prepared originally in English and translated into the local language (Amharic) for the purpose of data collection and then it was translated back to English to maintain the consistency of the tool.

The questionnaire had socio-demographic variables, husband/partner-related variables, and reproductive/obstetrics -related variables. For data collection, 11 diploma nurses and 11 guidance counselors were involved under the supervision of the investigators and supervisors.

\section{Data quality control}

A one-day training was given for data collectors and supervisors. The data were daily checked for completeness and accuracy by the principal investigator and supervisors.

A pretest was conducted on $5 \%$ of the sample size in the non-selected kebele of the district to ensure the validity, reliability, and clarity of the data collection instrument. Based on the findings from the pretest, modification on the questionnaire was done, and the arrangement of questions was revised.

\section{Study variables and measurements}

Initiation of maternal health service (utilization of ANC) was the first outcome variable. It was considered if a woman received one or more ANC visits during her pregnancy period [14] .

Continuity of maternal health service was the second outcome variable. Continuity of maternal health service was considered if a woman received at least one antenatal care visit during her pregnancy and gave birth at a health facility [14].

\section{Statistical analysis}

The data were first checked manually for completeness and then coded, cleaned, and entered into Epi data version 3.1 software. The data were exported to Statistical Package for Social Science (SPSS) version 20 for data analysis. Descriptive statistics (like mean, standard deviation, frequencies, and percentages) were used to describe the study population in relation to dependent and independent variables. Results were presented in text and tables.

Binary logistic regression (bivariable and multivariable logistic regression) was used to identify statistically significant independent variables, and independent variables having a $p$-value less than 0.2 in the bi-variable analysis were entered into multivariable binary logistic regression. A p-value $<0.05$ in the multivariable analysis was used to declare statistically significant variables. 
Hosmer-Lemeshow goodness-of-fit test was used to test model fitness and declared good fitted at a p-value of > 0.05. An AOR with 95\% CI was reported to show the strength of associations among the independent and outcome variables.

\section{Results}

\section{Respondents' socio-demographic characteristics}

Of the overall sample required $(N=651), 621$ participants were included in the study, giving a response rate of $95.4 \%$. The mean age of the women was 30.85 (SD \pm 6.56) years. The majority $352(56.7 \%)$ of the respondents were between 25 and 35 years old, followed by the age group of $>35$, years, $159(25.6 \%)$. Two hundred twentyseven (36.6\%) were housewives and 225(36.2\%) were farmers by occupation. The largest portion of the participants $(473(76.2 \%))$ were Orthodox Christians by religion. Five hundred thirteen (82.6) were currently married and 455(73.3\%) were rural residents. Around $46.1 \%$ of the women had access to mass media and $77.1 \%$ of the women had autonomy in healthcare decision-making (Table 1).

\section{Initiation (utilization) of antenatal care}

In this study, the initiation of maternal health service (women who received at least one antenatal care service) was $60.9 \%$ (95\% CI: 57.2, 65.1\%).

\section{Factors associated with utilization of antenatal care}

Age, marital status, women's educational status, autonomy for health care decision-making, exposure to media, wanted pregnancy, and parity had significant association with the initiation of antenatal care.

Younger women were more likely to utilize antenatal care $(\mathrm{AOR}=1.7$ 95\% CI: $(1.0,2.88))$ compared to those older women. Married women had higher odds of utilizing antenatal care $(\mathrm{AOR}=1.6,95 \% \mathrm{CI}$ : $(1.01,2.76)) \mathrm{com}-$ pared to those single ones. Women with formal education were more likely to utilize antenatal care $(\mathrm{AOR}=2.9,95 \%$ CI: $(1.30,6.72))$ compared to those women who had no formal education, and women who had the autonomy in health care decision -making were more likely to utilize antenatal care $(\mathrm{AOR}=3.71,95 \% \mathrm{CI}$ : $(2.36,6.02))$ compared to their counterparts. Women who had exposure to media were more likely to use antenatal care $(\mathrm{AOR}=2.8,95 \% \mathrm{CI}:(1.78,4.6))$ compared to those women who had no exposure to media. Women with wanted pregnancies were more likely to use antenatal care $(\mathrm{AOR}=3.695 \% \mathrm{CI}:(2.2,5.95)$ compared to those women whose pregnancies were unwanted. Para 1-2 women were less likely to utilize antenatal care (AOR $=0.34,95 \% \mathrm{CI}:(0.16,0.71)$ compared to para five and above women. In addition, para 3-4 women were less likely to utilize antenatal care than para five and above women (Table 2).

\section{Continuity of maternal health care service}

In our study, around $61 \%$ of the women had antenatal care. Of those women who had antenatal care visit, 77.5\% (95\% CI: 73, 81.7\%) continued to use services provided by skill birth attendants while delivery. On the other hand, $22.5 \%$ discontinued utilizing services by skilled birth attendants during delivery.

\section{Factors associated with continuation of maternal health care services}

In the multivariable analysis, only women's educational status, autonomy in health care decision -making, and counseling during antenatal care were associated with the continuation of maternal health care service (antenatal care to skilled birth delivery).

Women with formal education were more likely to continue from antenatal care to skilled birth delivery $(\mathrm{AOR}=4.65,95 \% \mathrm{CI}:(1.37,15.7))$ compared to those women who had no formal education. Besides, women who had health care decision-making autonomy were 2.6 times more likely to continue from antenatal care to skilled birth delivery (AOR $=2.62,95 \%$ CI: $(1.0,6.82)$ compared to those who had no autonomy to health care decision-making. Those women who had got counseling services during their pregnancy had higher odds of continuation from antenatal care to skilled birth delivery $\mathrm{AOR}=2.8895 \% \mathrm{CI}:(1.21,6.83)$ compared to their counterparts (Table 3 ).

\section{Discussion}

This study examined the factors influencing the initiation and continuation of maternal health care services utilization. Accordingly, the findings of this study indicated that the utilization of antenatal care services was 60.9\% (95\% CI: 57.2, 65.1\%), which is lower than results of studies done in an urban area of Bhubaneswar, India (86.1\%) [15], Entebbe, Uganda (96\%) [16], Southern Ethiopia (77.4\%) [17], Ari Woreda, South Omo Zone (87\%) [18] but higher than studies conducted in MenitShasha District, Ethiopia (15.5\%) [19] and Bangladesh (55\%) [20]. This observed variation might be due to differences in socio-demographic characteristics like residence as our study was conducted in both urban and rural areas, differences in the study population, and the measurement tools used across the studies.

Around $77.5 \%$ (95\% CI: 73, 81.7\%) of the women had continued to receive skilled birth delivery once they received antenatal care. This result is consistent with a study done in Cambodia (71\%) [21], but higher than studies carried out in nine countries of South Asia and Sub Saharan Africa, which were (28.5\%) [2], Nigeria 
Table 1 Background characteristics of women who delivered in the past one year in Enemay district, East Gojjam, Ethiopia

\begin{tabular}{|c|c|c|c|}
\hline Variables & Category & Frequency & Percentage \\
\hline \multirow[t]{3}{*}{ Age of the respondents } & $15-24$ & 110 & 17.7 \\
\hline & $25-35$ & 352 & 56.7 \\
\hline & $>35$ & 159 & 25.6 \\
\hline \multirow[t]{2}{*}{ Religion } & Orthodox & 473 & 76.2 \\
\hline & Others & 148 & 23.8 \\
\hline \multirow[t]{3}{*}{ Marital status of the woman } & Single/widowed divorced & 108 & 17.4 \\
\hline & Married & 513 & 82.6 \\
\hline & Cannot read and write & 219 & 35.3 \\
\hline \multirow[t]{4}{*}{ Educational status of the woman } & Read and write & 125 & 20.1 \\
\hline & Primary & 163 & 26.2 \\
\hline & Secondary and above & 114 & 18.4 \\
\hline & Housewife & 228 & 36.7 \\
\hline \multirow[t]{3}{*}{ Respondent's occupation } & Merchant & 127 & 20.5 \\
\hline & Farmer & 226 & 36.4 \\
\hline & Employer & 40 & 6.4 \\
\hline \multirow[t]{3}{*}{ Number of children } & $1-2$ & 298 & 48.0 \\
\hline & $3-4$ & 237 & 38.2 \\
\hline & $\geq 5$ & 86 & 13.8 \\
\hline \multirow[t]{2}{*}{ Residence } & Rural & 455 & 73.3 \\
\hline & Urban & 166 & 26.7 \\
\hline \multirow[t]{2}{*}{ Autonomy to health care decision making } & Yes & 479 & 77.1 \\
\hline & No & 142 & 22.9 \\
\hline \multirow[t]{2}{*}{ Respondent exposure to media } & Yes & 286 & 46.1 \\
\hline & No & 335 & 53.9 \\
\hline \multirow[t]{2}{*}{ Wanted pregnancy } & Yes & 493 & 79.4 \\
\hline & No & 128 & 20.6 \\
\hline \multirow[t]{4}{*}{ Educational status of husband/partner } & cannot read write & 165 & 26.6 \\
\hline & Read and write & 172 & 27.7 \\
\hline & Primary & 117 & 18.8 \\
\hline & Secondary and above & 167 & 26.9 \\
\hline \multirow[t]{3}{*}{ Husband's occupation } & Merchant & 213 & 34.3 \\
\hline & Farmer & 353 & 56.8 \\
\hline & Employer & 55 & 8.9 \\
\hline
\end{tabular}

(61.9\%) [22], Nepal (39\%) [23]. This discrepancy might be due to differences in accessibility of services, measurement, and difference in socio-demographic characteristics of respondents.

With regard to the associated factors, a significant association was observed with women's age. It was indicated that being in the age class of 15-24 years increases the odds of ANC initiation by 1.7 times compared to those who were in the age group of 25-35 years. Similar earlier results were also reported in Addis Ababa [2123]. This may be due to the relative childbearing inexperience (low parity) as they may be newlyweds or adolescents and therefore be more likely to seek out ANC earlier than their older counterparts due to ignorancel limited knowledge of pregnancy. Confounding effect of by parity on age may also have affected the relationship between age and ANC use as low parity was associated with early ANC booking and increased number of ANC contacts [24, 25].

Unsurprisingly, marital status was found to be an important predictor in affecting the initiation of antenatal care. It revealed that married women have been found to utilize antenatal care than unmarried ones. This result is congruent with a study conducted earlier [26]. This is 
Table 2 factors associated with utilization of antenatal care among women who delivered in the past one year in Enemay district, East Gojjam, Ethiopia

\begin{tabular}{|c|c|c|c|c|c|}
\hline \multirow[t]{2}{*}{ Variables } & \multirow[t]{2}{*}{ Category } & \multicolumn{2}{|l|}{ ANC } & \multirow[t]{2}{*}{ COR 95\%Cl } & \multirow[t]{2}{*}{ AOR 95\%Cl } \\
\hline & & YES & NO & & \\
\hline \multirow[t]{3}{*}{ Age group } & $15-24$ & $74(67.3 \%)$ & $36(32.7 \%)$ & $2.030(1.22-3.36)$ & $1.8(0 . .88,3.99)$ \\
\hline & $25-35$ & $224(63.6 \%)$ & $128(36.4 \%)$ & $1.728(1.18-2.52)$ & $1.7(1.0,2.88)^{*}$ \\
\hline & $>35$ & $80(50.3 \%)$ & 79 (49.7\%) & & 1 \\
\hline \multirow[t]{2}{*}{ Respondent's marital status } & Married & $320(62.4 \%)$ & 193(37.6\%) & $1.43(0.94-2.17)$ & $1.6(1.01,2.76)^{*}$ \\
\hline & Single & $58(53.7 \%)$ & $50(46.3 \%)$ & 1 & 1 \\
\hline \multirow[t]{2}{*}{ Educational status of the woman } & Have formal education & $275(54.2 \%)$ & $232(45.8 \%)$ & $7.9(4.1,15.0)$ & $2.9(1.30,6.72)^{*}$ \\
\hline & Have no formal education & 103(90.4\%) & $11(9.6 \%)$ & 1 & 1 \\
\hline \multirow[t]{3}{*}{ Parity } & $1-2$ & $196(65.8 \%)$ & $102(34.2 \%)$ & $1.52(0.93-2.45)$ & $0.34(0.16,0.71)^{*}$ \\
\hline & $3-4$ & $134(56.5 \%)$ & $103(43.5 \%)$ & $1.03(0.63-1.69)$ & $0.46(0.24,0.88)^{*}$ \\
\hline & $\geq 5$ & $48(55.8 \%)$ & $38(44.2 \%)$ & & 1 \\
\hline \multirow[t]{2}{*}{ Residence } & Rural & $249(54.7 \%)$ & $206(45.3 \%)$ & $0.35(0.23-0.52)$ & $1.2(0.64,2.24)$ \\
\hline & Urban & $129(77.7 \%)$ & $37(22.3 \%)$ & 1 & 1 \\
\hline \multirow[t]{2}{*}{ Autonomy in health care decision making } & Yes & $338(70.6 \%)$ & $141(29.4 \%)$ & $6.11(4.0-9.23)$ & $3.7(2.36,6.02)^{*}$ \\
\hline & No & $40(28.2 \%)$ & $102(71.8 \%$ & & 1 \\
\hline \multirow[t]{2}{*}{ Media exposure of the woman } & Yes & $230(80.4 \%)$ & $56(19.6 \%)$ & $5.18(3.61-7.46)$ & $2.8(1.78,4.6)^{*}$ \\
\hline & No & $148(44.2 \%)$ & $187(55.8 \%)$ & 1 & 1 \\
\hline \multirow[t]{2}{*}{ Wanted pregnancy } & Yes & $336(68.2 \%)$ & 157(31.8\%) & $4.38(2.89-6.63)$ & $3.6(2.2,5.95)^{*}$ \\
\hline & No & $42(32.8 \%)$ & $86(67.2 \%)$ & 1 & 1 \\
\hline \multirow[t]{2}{*}{ Husband's educational status } & Have formal education & $241(53.1 \%)$ & $213(46.9 \%)$ & $4(2.6,6.24)$ & $1.1(0.60,2.04)$ \\
\hline & Have no formal education & 137 (82.0\%) & $30(18.0 \%)$ & 1 & 1 \\
\hline \multirow[t]{3}{*}{ Husband's occupational status } & Merchant & $153(71.8 \%)$ & $60(28.2 \%)$ & $0.09(0.02-0.40)$ & $0.12(0.02,0.56)$ \\
\hline & Farmer & $172(48.7 \%)$ & $181(51.3 \%)$ & $0.03(0.09-0.15)$ & $0.1(0.02,0.55)$ \\
\hline & Employer & $53(96.4 \%)$ & $2(3.6 \%)$ & 1 & 1 \\
\hline
\end{tabular}

partially secondary to support from partners and the social acceptability of pregnancy. This is thought to encourage the attendance of antenatal care. Adolescents and unmarried younger women hide their pregnancy to avoid social embarrassment which in turn delays their initiation of antenatal care visits [27]. In a study done in Ethiopia, single or divorced mothers were more likely to attend antenatal care than mothers who were married [28]. Furthermore, the findings of this study revealed that formal education was associated with the initiation of antenatal care. This result concurs with former studies $[29,30]$. It was reported that improving women's education increases the utilization of maternal healthcare services, including antenatal care. In a study conducted in Sudan, it was revealed that lack of maternal education increased the odds of non-use of antenatal care [31]. This could be due to the fact that women with formal education have greater confidence to take actions regarding their own health and they have awareness on advantage of utilizing health services compared to women who had no education [32, 33]. In addition to that, education makes women more empowered and confident by giving them information on their health, so they can decide to seek care during pregnancy or delivery [34].

Moreover, in our analysis, women's health care decision-making autonomy was positively associated with the initiation of antenatal care. This finding is consistent with the studies conducted so far $[35,36]$. The plausible explanation might be that autonomous women would make the right choices and access quality healthcare at all times particularly during antenatal care [37].

This study also revealed that women who have been using mass media were 2.8 times more likely to utilize antenatal care services than women who did not use any type of mass media. Similar findings were reported in the study done in Ethiopia in 2017, [38], 2019 [39], and Indonesia [40]. This might be because using mass media may increase the knowledge and practices of the women to utilize proper antenatal care for the benefits of the health of the mother and newborn babies.

Our analysis showed that women whose pregnancies were wanted were more likely to receive antenatal care. This is supported by studies conducted in other 
Table 3 Factors associated with continuation of maternal health care from antenatal care to skill birth delivery among women who delivered in the past one year in Enemay district, East Gojjam

\begin{tabular}{|c|c|c|c|c|c|}
\hline \multirow[t]{2}{*}{ Variables } & \multirow[t]{2}{*}{ Category } & \multicolumn{2}{|c|}{ Continuity of maternal health service } & \multirow[t]{2}{*}{ COR $95 \% \mathrm{Cl}$} & \multirow[t]{2}{*}{ AOR } \\
\hline & & YES & NO & & \\
\hline \multirow[t]{3}{*}{ Age group } & $15-24$ & $61(82.4 \%)$ & $13(17.6 \%)$ & $1.2(0.56,2.82)$ & $0.93(0.28,3.07)$ \\
\hline & $25-35$ & $169(75.4 \%)$ & $55(24.6 \%)$ & $0.82(0.44,1.53$ & $0.81(0.34,1.91)$ \\
\hline & $>35$ & $63(78.8 \%)$ & $17(21.2 \%)$ & 1 & 1 \\
\hline \multirow[t]{2}{*}{ Marital Status of the woman } & Married & $250(78.1 \%)$ & $70(21.9 \%)$ & $1.24(0.65,2.37)$ & $1.16(0.53,2.56)$ \\
\hline & Single/divorced/ & $43(74.1 \%)$ & $15(25.9 \%)$ & 1 & 1 \\
\hline \multirow[t]{2}{*}{ Educational status of the woman } & Have formal education & $97(94.2 \%)$ & $6(5.8 \%)$ & $6.51(2.74,15.47)$ & $4.65(1.37,15.7)^{*}$ \\
\hline & Have no formal education & $196(71.3 \%)$ & $79(28.7 \%)$ & 1 & \\
\hline \multirow[t]{4}{*}{ Respondent's occupation } & Housewife & $135(92.5 \%)$ & $11(7.5 \%)$ & $0.64(0.13,3.04)$ & $3.56(0.47,26.7)$ \\
\hline & Merchant & $74(79.6 \%)$ & $19(20.4 \%)$ & $0.2(0.04,0.92)$ & $0.58(0.09,3.52)$ \\
\hline & Farmer & $46(46.5 \%)$ & $53(53.5 \%)$ & $0.04(0.01,0.20)$ & $0.18(0.02,1.3)$ \\
\hline & Employer & $38(95 \%)$ & $2(5 \%)$ & 1 & 1 \\
\hline \multirow[t]{3}{*}{ Parity } & $1-2$ & 153(78.1\%) & $43(21.9 \%)$ & $0.93(0.43,2.03)$ & $0.65(0.20,2.10)$ \\
\hline & $3-4$ & $102(76.1 \%)$ & $32(23.9 \%)$ & $0.83(0.37,1.87)$ & $1.13(0.40,3.15)$ \\
\hline & $\geq 5$ & $38(79.2 \%)$ & $10(20.8 \%)$ & 1 & 1 \\
\hline \multirow[t]{2}{*}{ Residence } & Rural & 169(67.9\%) & $80(32.1 \%)$ & $0.08(0.03,0.21)$ & - \\
\hline & Urban & 124(96.1\%) & $5(3.9 \%)$ & 1 & - \\
\hline \multirow[t]{2}{*}{ Autonomy in decision making } & Yes & $268(79.3 \%)$ & $70(20.7 \%)$ & $2.29(1.15,4.58)$ & $2.62(1.0,6.82)^{*}$ \\
\hline & No & $25(62.5 \%)$ & $15(37.5 \%)$ & 1 & 1 \\
\hline \multirow[t]{2}{*}{ Media exposure of the respondent } & Yes & 193(83.9\%) & $37(16.1 \%)$ & $2.5(1.53,4.09)$ & $1.43(0.74,2.76)$ \\
\hline & No & $100(67.6 \%)$ & $48(32.4 \%)$ & 1 & 1 \\
\hline \multirow[t]{2}{*}{ Wanted pregnancy } & Yes & $261(77.7 \%)$ & 75 (22.3\%) & $1.08(0.51,2.31)$ & $0.65(0.26,1.65)$ \\
\hline & No & $32(76.2 \%)$ & $10(23.8 \%)$ & 1 & 1 \\
\hline \multirow[t]{2}{*}{ Husband's educational status } & Have formal education & $120(87.6 \%)$ & $17(12.4 \%)$ & $2.77(1.55,4.95)$ & $0.86(0.37,2.01)$ \\
\hline & Have no formal education & $173(71.8 \%)$ & $68(28.2 \%)$ & 1 & 1 \\
\hline \multirow[t]{2}{*}{ Counseling during ANC } & Yes & $266(79.6 \%)$ & $68(20.4 \%)$ & $2.46(1.27,4.77)$ & $2.88(1.21,6.83)^{*}$ \\
\hline & No & $27(61.4 \%)$ & $17(38.6 \%)$ & 1 & \\
\hline
\end{tabular}

countries [41-43]. It is possible that women whose pregnancies were unintended may fear the social ramifications of an unplanned pregnancy, so they may avoid health services utilization.

Interestingly, this study indicated that an increase in parity increases the likelihood of uptake/ initiation of antenatal care. There is no study in agreement with this finding. The possible explanation for this result might be that when parity increases women might have past obstetrics complications which lead them to seek maternal health care services including antenatal care.

Counseling during antenatal care was significantly associated with the continuation of antenatal care to skilled delivery. The possible reason might be that women who were counseled during antenatal care might receive information about birth preparedness and complication readiness including being assisted by skilled birth attendants during delivery. Educational status was also another factor affecting both the initiation and continuation of maternal health care service utilization. This is in line with studies done in Pakistan and Cambodia $[44,45]$. The possible justification for this might be that those educated women might have better health knowledge about the importance of delivery with skilled birth attendants. The other possible reason could be that education is likely to enhance and develop greater confidence and capability to make decisions about their own health, and educated women may probably have a good chance to approach the written information about maternal health service.

Having the autonomy in health care decision-making was also positively associated with both initiation and continuation of maternal health care service utilization which is consistent with a study conducted in Pakistan [44]. A possible explanation could be that women who have autonomy in decision-making are more likely to 
have a higher level of autonomy in health care, which might lessen their reproductive behavior risks [46]. Another study has confirmed that women's control over household resources (ability to keep money aside) has a significant positive effect on both the demand for prenatal care and the probability of hospital delivery [47].

\section{Limitations of the study}

This study acknowledged some important possible limitations that should be considered when interpreting the results. First, the study was cross-sectional, a design that does not permit to establish cause-effect relationships. Second, social desirability bias and recall bias might be introduced as information in the survey was based on self-reports of the study participants.

\section{The added value of this work}

This study tried to assess the magnitude of the initiation of antenatal care service and the continuation of antenatal care to institutional delivery. Moreover, the determinant factors of initiation and continuation of the services have been explored, which other earlier studies did not address.

\section{Implications for policymakers}

The evidence from these findings calls for policymakers to play a role in enhancing the utilization of antenatal care and skilled birth attendant (institutional delivery) services through scaling up the awareness of those illiterate women at the community level about the service through appropriate information outlets such as mainstream media, proper counseling during antenatal care follow-up.

\section{Conclusions}

This study showed that the initiation and continuity of maternal health care services utilization are low in the study area compared to the national target. Age, marital status, residence, women's educational status, autonomy to health care decision making, exposure to media, wanted pregnancy, and parity were factors significantly affecting the initiation of antenatal care, whereas women's educational status, autonomy to health care decision making, and counseling during antenatal care were predictors influencing the continuation of maternal health care services (antenatal care to skilled birth delivery).

\section{Abbreviations}

ANC: Antenatal Care; SBA: Skilled Birth Attendant; AOR: Adjusted Odds Ratio; Cl: Confidence Interval; CSA: Central Statistics Agency; SPSS: Statistical Package for Social Science; WHO: World Health Organization; GDP: Gross domestic product

\section{Acknowledgements}

We are very indebted to Enemay district health office for permitting us to conduct the study and providing the necessary preliminary information while conducting this study. We do wish to extend our gratitude to the study participants, supervisors, and data collectors.

\section{Authors' contributions}

All stated authors: ASL and ZNA are involved in the study from the inception to design, acquisition of data, analysis and interpretation and drafting of the manuscript. All authors read and approved the final manuscript.

\section{Funding}

The author(s) received no specific funding for this work.

\section{Availability of data and materials \\ The dataset analyzed during the current study available from the corresponding author on reasonable request.}

\section{Declarations}

\section{Ethics approval and consent to participate}

The study was conducted after obtaining ethical clearance from Haramaya University Institutional Health Research Ethics Review Committee (IHRERC). An official letter of cooperation was written to Enemay District health office. After a clear and detailed explanation of the purpose, risks, and benefits of the study, written informed consent was obtained from each of the mothers/study participants. For those participant less than eighteen year oral assent was taken from the respondents and written informed consent was taken from their parent or guardian. We told mothers, participation was on a voluntary basis and that they can withdraw at any time if they are not comfortable during the interview. Personal identifiers were not included in the written tool to ensure confidentiality.

\section{Consent for publication}

Not applicable

\section{Competing interests}

The authors have declared that they have no competing of interests.

\section{Author details}

${ }^{1}$ Department of Midwifery, College of Medicine and Health Sciences, Wollo University, Dessie, Ethiopia. 'Department of Women's and family health, School of Midwifery, College of Medicine and Health Sciences, University of Gondar, Gondar, Ethiopia.

Received: 29 March 2021 Accepted: 7 September 2021

Published online: 28 September 2021

\section{References}

1. Akinyemi JO, Afolabi RF, Awolude OA. Patterns and Determinants of Dropout from Maternity Care Continuum in Nigeria. BMC Pregnancy and Childbirth. 2016;16(1):282. https://doi.org/10.1186/s12884-016-1083-9.

2. Kerber K, Johnson J, Bhutta Z, Okong P, Starr A, Lawn J. Continuum of care for maternal, newborn, and child health: from slogan to service delivery 2007;370(1358):69.

3. Osaki K, Hattori T, Kosen S. The role of home-based records in the establishment of a continuum of care for mothers, newborns, and children in Indonesia. Glob Health Action. 2013;6(1):20429. https://doi.org/10.3402/ gha.v6i0.20429.

4. WHO. Defining Competent Maternal and Newborn Health Professionals. Geneva: World Health Organization; 2018. Licence: Cc By-Nc-Sa 3.0 lgo 2018. Available from: http://www.who.int/iris/handle/10665/272817. .

5. Organization $W H$. Trends in maternal mortality 2000 to 2017: estimates by WHO. UNFPA, World Bank Group and the United Nations Population Division: UNICEF; 2019.

6. CSA. Central Statistical Agency (CSA) [Ethiopia] and ICF. 2016. Ethiopia Demographic and Health Survey 2016: Key Indicators Report. Addis Ababa, Ethiopia, and Rockville, Maryland, USA. CSA and ICF 2016. Available from: https://www.usaid.gov/../Ethiopia\%20DHS\%202016\%20KIR\%20-\%20Final\%2 010-1... 
7. WHO. Maternal Mortality 2018. Available from: www.who.int > News > Fact sheets > Detail.

8. Wang W, Hong R Levels and Determinants of Continuum of Care for Maternal and Newborn Health In Cambodia- Evidence from A PopulationBased Survey BMC Pregnancy and Childbirth 2015;15(62).

9. Landers C, Moger S. Maternal and Newborn Health: A Global Challenge U.S. Fund for UNICEF Youth Report The State of the World's Children 2009. 2009

10. Kirigia J. M, Oluwole D., Mwabu G. M , Gatwiri D, Lenity H, Kainyu effects of maternal mortality on gross domestic product (GDP) in the WHO African region. Afr J Health Sci 2006;13, 3, DOI: https://doi.org/10.4314/ajhs.v12i3.3 0801.

11. Moucheraud C, Worku A, Molla M, Finlay J. E, Leaning J, Yamin A. E. Consequences of maternal mortality on infant and child survival: a 25-year longitudinal analysis in Butajira Ethiopia (1987-2011). 2015

12. Lachin JM. Introduction to sample size determination and power analysis for clinical trials. Control Clin Trials. 1981;2(2):93-113. https://doi.org/10.1016/ 0197-2456(81)90001-5.

13. Chandhiok N, Dhillon BS, Kambo I, Saxena NC. Determinants of antenatal care utilization in rural areas of India: a cross-sectional study from 28 districts (an ICMR task force study). J Obstet Gynecol India. 2006;56(1):47-52.

14. Dennis ML, Benova L, Abuya T, Quartagno M, Bellows B, Campbell OM. Initiation and continuity of maternal healthcare: examining the role of vouchers and user-fee removal on maternal health service use in Kenya. Health Policy Plan. 2019;34(2):120-31. https://doi.org/10.1093/heapol/czz004.

15. Sarangi L. Factors Affecting Utilization of Maternal Health Care Services in Urban area of Bhubnaneswar, India. J Pharm Pract Comm Med. 2017;3(3).

16. Tann C., Kizza M., Morison L., Mabey D., Muwanga M. a, . kH. Use of antenatal services and delivery care in Entebbe, Uganda: a community survey. BMC Pregnancy Childbirth 2007;7(23), 7, 1, DOl: https://doi.org/10.11 86/1471-2393-7-23.

17. Regassa N. Antenatal and Postnatal Care Service Utilization in Southern Ethiopia:A Population-Based Study African Health Sciences 2011;11(3):390397.

18. Wondimu W, Girma M, Agedew E. Antenatal Care Utilization and Associated Factors among Reproductive Age Mother in Ari Woreda, South Omo Zone. Reprod Syst Sex Disord. 2017;6(1).

19. Teka SW. Factors influencing antenatal care service utilization among pregnant women in pastoralist Community in Menit-Shasha District, Ethiopia. Int J Med Res Health Sci. 2018;7(2319-5886):143-56.

20. Rahman MM, Rahman MM, Tareque MI, Ferdos J, Jesmin SS. Maternal pregnancy intention and professional antenatal care utilization in Bangladesh: a Nationwide population-based survey. PLoS One. 2016;11(6): e0157760. https://doi.org/10.1371/journal.pone.0157760.

21. Kwast BE, Liff JM. Factors associated with maternal mortality in Addis Ababa, Ethiopia. Int J Epidemiol. 1988;17(1):115-21. https://doi.org/10.1093/ije/1 7.1.115.

22. Activities UNFfP, Health DBCfRoWs. Maternal Mortality Update 2004: Delivering Into Good Hands: United Nations Population Fund; 2004.

23. Okedo-Alex IN, Akamike IC, Ezeanosike OB, Uneke CJ. Determinants of antenatal care utilisation in sub-Saharan Africa: a systematic review. BMJ Open. 2019;9(10):e031890. https://doi.org/10.1136/bmjopen-2019-031890.

24. Hajizadeh S, Ramezani Tehrani F, Simbar M, Farzadfar F. Factors influencing the use of prenatal care: a systematic review. J Midwifery Reprod Health. 2016:4(1):544-57.

25. Tesfaye G, Loxton D, Chojenta C, Semahegn A, Smith R. Delayed initiation of antenatal care and associated factors in Ethiopia: a systematic review and meta-analysis. Reprod Health. 2017;14(1):1-17. https://doi.org/10.1186/s12 978-017-0412-4

26. Simkhada B. Teijlingen ERv, porter M, Simkhada P. factors affecting the utilization of antenatal care in developing countries: systematic review of the literature. J Adv Nurs. 2008;61(3):244-60. https://doi.org/10.1111/j.1365-2 648.2007.04532.x.

27. Pell C, Meñaca A, Were F, Afrah NA, Chatio S, Manda-Taylor L, et al. Factors affecting antenatal care attendance: results from qualitative studies in Ghana. Kenya Malawi PloS one. 2013;8(1):e53747. https://doi.org/10.1371/ journal.pone.0053747.

28. Getachew T, Abajobir AA, Aychiluhim M. Focused antenatal care service utilization and associated factors in Dejen and Aneded districts, Northwest Ethiopia. Primary Health Care: Open Access. 2014;4(4):1-8.

29. Zhang J, Long Y, Wang L, Dang Z, Zhang T, Song X, et al. Consensus genetic linkage map construction and QTL mapping for plant height- related traits in linseed flax (Linum usitatissimum L.). BMC Plant Biol. 2018; 18(1):160.

30. Moyer CA, Mustafa A. Drivers and deterrents of facility delivery in subSaharan Africa: a systematic review. Reprod Health. 2013;10(1):40. https://doi. org/10.1186/1742-4755-10-40.

31. Mustafa MH, Mukhtar AM. Factors associated with antenatal and delivery care in Sudan: analysis of the 2010 Sudan household survey. BMC Health Serv Res. 2015;15(1):452. https://doi.org/10.1186/s12913-015-1128-1.

32. Babalola S, Fatusi A. Determinants of use of maternal health services in Nigeria-looking beyond individual and household factors. BMC Pregnancy Childbirth. 2009;9(1):43. https://doi.org/10.1186/1471-2393-9-43.

33. Tiruneh FN, Chuang K-Y, Chuang Y-C. Women's autonomy and maternal healthcare service utilization in Ethiopia. BMC Health Serv Res. 2017;17(1): 718. https://doi.org/10.1186/s12913-017-2670-9.

34. Jejeebhoy SJ. Women's education, autonomy, and reproductive behaviour: experience from developing countries. OUP Catalogue. 1995.

35. Asweto CO, Ouma J, Aluoch J, Obonyo C. Women empowerment and skilled attendance/facility delivery in a rural community of western Kenya; 2014.

36. Baral Y, Lyons K, Skinner J, Van Teijlingen E. Determinants of skilled birth attendants for delivery in Nepal. Kathmandu Univ Med J. 2010;8(3):325-32. https://doi.org/10.3126/kumj.v8i3.6223.

37. Ameyaw EK, Tanle A, Kissah-Korsah K, Amo-Adjei J. Women's health decision-making autonomy and skilled birth attendance in Ghana. Int J ReprodMed. 2016;2016:1-9. https://doi.org/10.1155/2016/6569514.

38. Yaya S, Bishwajit G, Ekholuenetale $M$, Shah V, Kadio B, Udenigwe O. Timing and adequate attendance of antenatal care visits among women in Ethiopia. PLoS One. 2017;12(9):e0184934. https://doi.org/10.1371/journal. pone.0184934.

39. Basha GW. Factors affecting the utilization of a minimum of four antenatal care services in Ethiopia. Obstet Gynecol Int. 2019;2019:1-6. https://doi.org/1 $0.1155 / 2019 / 5036783$.

40. Titaley CR, Dibley MJ, Roberts CL. Factors associated with underutilization of antenatal care services in Indonesia: results of Indonesia demographic and health survey 2002/2003 and 2007. BMC Public Health. 2010;10(1):485. https://doi.org/10.1186/1471-2458-10-485.

41. Dibaba Y, Fantahun M, Hindin MJ. The effects of pregnancy intention on the use of antenatal care services: systematic review and meta-analysis. Reprod Health. 2013;10(1):50. https://doi.org/10.1186/1742-4755-10-50.

42. Gupta S, Yamada G, Mpembeni R, Frumence G, Callaghan-Koru JA, Stevenson $\mathrm{R}$, et al. Factors associated with four or more antenatal care visits and its decline among pregnant women in Tanzania between 1999 and 2010. PLoS One. 2014;9(7):e101893. https://doi.org/10.1371/journal.pone.01 01893.

43. Ochako R, Gichuhi W. Pregnancy wantedness, frequency and timing of antenatal care visit among women of childbearing age in Kenya. Reprod Health. 2016;13(1):51. https://doi.org/10.1186/s12978-016-0168-2.

44. Iabal S, Maqsood S, Zakar R, Zakar M. Z, Fischer F. Continuum of Care in Maternal, Newborn and Child Health In Pakistan: Analysis of Trends and Determinants from 2006 to 2012 BMC Health Services Research 2017;17:189.

45. Wang W, Hong R. Completing the Continuum of Care for Maternal and Newborn Health in Cambodia: Who Drops Out? DHS Further Analysis Reports No. 85. Calverton, Maryland, USA: ICF International. 2013. Available from: Internet: http://www.measuredhs.com.

46. Dyson T, Moore M. On kinship structure, female autonomy, and demographic behavior in India. Popul Dev Rev. 1983;9(1):35-60. https://doi. org/10.2307/1972894.

47. Maitra P. Parental bargaining, health inputs and child mortality in India. J Health Econ. 2004;23(2):259-91. https://doi.org/10.1016/j.jhealeco.2003.09. 002.

\section{Publisher's Note}

Springer Nature remains neutral with regard to jurisdictional claims in published maps and institutional affiliations. 